\title{
Impact of Using Simulation Based Learning on Nursing Students' Performance, Self-efficacy, Satisfaction and Confidence during Pediatric Injection Administration
}

\author{
Aml Ahmed Ali Gamal El-deen \\ B. SC. Nursing, Faculty of Nursing, Tanta University

\section{Prof. Dr. Rahma Soliman Bahgat} \\ Professor of Pediatric Nursing, Faculty of Nursing, Tanta University \\ Dr. Amira Mohamed Saed Khalil \\ Lecturer of Pediatric Nursing, Faculty of Nursing, Tanta University
}

\section{Abstract}

Background; Simulation is the imitation of the operation of a real-world process or system over time. The aim of this study was to evaluate the impact of using simulation-based learning on nursing students' performance, self-efficacy, satisfaction and confidence during pediatric injection administration. Materials and Method: the subjects consisted of 150 pediatric nursing students in the third year, Faculty of Nursing, Tanta University, who were divided into two groups. Four tools were used to collect data: A structured Questionnaire Schedule, Learner Satisfaction and Self Confidence in Learning Scale, Self-efficacy Scale, and Pediatric Injection Observational Checklist. The results revealed that there was statistically significant difference in students' knowledge and performance after simulation-based learning (SBL). The majority of students' answers were correct after SBL. All students were satisfied with SBL, most of them were confident and had increased self-efficacy after SBL. The study concluded that there was a significant improvement in pediatric nursing students' performance regarding intravenous, intramuscular, and subcutaneous pediatric injection administration after SBL. The level of student's satisfaction, confidence, and self-efficacy was very high after SBL. This study concluded that students found SBL an effective instructional technique. Recommendations: Medical and nursing education programs should adopt simulation in undergraduate education, and should support the introduction of simulation-based learning as an important step in curriculum development.

Key words: Simulation, Based Learning, Performance, Self-efficacy, Satisfaction and Confidence, Pediatric Injection Administration.

\section{Introduction}

Nursing is a practice and active learning profession. Caring for patients has been the preferred method of achieving competency in nursing practice. Faced with increasingly complex clinical situations, nurses must respond with accurate clinical judgment. It is crucial to bridge the gap that exists between what students learn in the classroom and how 
they apply what they learn in their clinical practice. The major focus of clinical education is facilitating the development of knowledge application, accurate clinical judgment and skill development $(1,2)$.

The traditional teaching method of "see one, do one and teach one" which has long been used to teach nursing skills and to promote the acquisition of clinical expertise is no longer accepted as the best way to teach students. Only when nursing students have confidence in their own abilities, theyare able to shift focus to the needs of their patients. Shifting from their own needs to those of a patient is essential to being a safe and competent practitioner $^{(3)}$.

Simulation is designed to encourage active participation in the learning process allowing students to gain knowledge and develop psychomotor skills in a safe environment. There are three types of simulation with different abilities to mimic reality. Low-fidelity simulation uses manikins that are less similar to reality, such as Intravenous (IV) training arms, Intramuscular (IM) injection hips. Intermediate-fidelity simulation uses manikins that offer breath sounds, heart sounds and bowel sounds, and allow for initiation of IV therapy but lack the complexity and realism of patient scenarios ${ }^{(4)}$.
High-fidelity simulation (HFS) is an approach to experiential learning using manikins with actual physiological and pharmacological responses. Students can make, detect and correct patient care errors without negative consequences. HFS has been proposed as a novel, supplemental teaching-learning strategy to enhance the transfer of student confidence and competence from the classroom to the clinical nursing environment ${ }^{(4-6)}$.

Simulation is the imitation of the operation of a real-world process or system over time. The act of simulating something first requires that a model be developed; this model represents the key characteristics or behaviors/functions of the selected physical or abstract system or process. The model represents the system itself, whereas the simulation represents the operation of the system over time ${ }^{(7)}$. Simulation in education has been used at least since the time of World War II. Simulation in nursing education in the form of static manikins, role playing, and CPR manikins has also been utilized as a teaching modality for quite some time. High-fidelity simulation is a relatively new area in nursing education and utilizes high technology simulation monitors and computers. Researchers have investigated the potential advantages of using HFS in the training of nursing skills and 
evaluated the changes in students' confidence and clinical competence after simulation ${ }^{(8-10)}$.

In recent decades, nursing instructors have tended to use simulation rather than traditional methods to increase satisfaction, self-efficacy, and selfconfidence of students. Self-efficacy is a characteristic that is believed to increase individual's ability to be successful at a task. Most newly graduated nurses do not have the required skills to perform psychomotor procedures. Difficulty in finding a safe clinical environment to provide good clinical experiences for students during the time of nursing education can be one of the causes ${ }^{(9,11)}$.

In fact, the more prevalent in pediatric units is that most children are being treated on an outpatient basis due to the crowdedness of hospitals. Therefore, nursing instructors who have the responsibility to provide rich clinical experiences for students and a safe care for children and their families, seek additional non-traditional methods to enhance the clinical experiences of students. Simulation in pediatric clinical nursing education allows students to actively learn and develop confidence in pediatric nursing care without the fear of putting the patient at risk ${ }^{(10-12)}$.

Considering students' self-confidence in pediatric clinical training is of great importance, because students are often anxious in the beginning of these courses. This is due to the small size of children and that they are more delicate than adults. Moreover, parents are usually present at the time of care, and this can be stressful and threatening for nursing students. Nursing education faces the challenge of preparing graduates to face the complexities that are found in today's health care environment ${ }^{(13-15)}$.

Simulation-based learning is increasingly being integrated into pediatric nursing education for students as well as novice nurses in practice. With simulation technology, undergraduate students can gain and improve skills in a safe, nonthreatening, experiential environment that also provides opportunities for decision making, critical thinking, and team building ${ }^{(16-18)}$. So, the aim of this study was toevaluate the impact of using simulation-based learning on nursing students' performance, self-efficacy, satisfaction and confidence during pediatric injection administration.

\section{Materials and Method}

Research design: A quasi experimental research design was used.

Setting: The study was conducted at the Clinical Pediatric Laboratory Skills for third year students, Faculty of Nursing, Tanta University. 
Subject: A total sample of 150 pediatric nursing students in the third year, Faculty of Nursing , Tanta University who got training in the period from August 2014 to December 2014 in the previous mentioned setting. The studied students were divided into two groups:

a) Group 1 (Control group): consisted of 75 pediatric nursing students studying with traditional teaching methods and was tested for each number group and allocation was randomly determined.

b) Group 2 (Study group): consisted of 75 pediatric nursing students studying with simulation -based learning.

The students were allocated to either control or study group by using cluster randomization.

Tools of data collection: Four tools were used to collect the data. These tools were:

Tool I: A Structured Questionnaire Schedule Regarding Students' Knowledge Related to Pediatric Injection Administration:

It was developed by the researcher after reviewing the related literature to assess the students' knowledge regarding pediatric injection administration. It comprised two main parts:

Part I: socio-demographic characteristics of the studied students which included: age, sex, residence and attendance of the related clinical training.
Part II: students' knowledge regarding pediatric injection administration which included: Different sites of injection, general guidelines, methods of injection, techniques, advantages and disadvantages of intravenous, intramuscular and subcutaneous pediatric injection administration, nursing role, and after care.

\section{Tool II. Learner Satisfaction and Self} Confidence in Learning Scale:

This scale was developed by the National League for Nursing (2009) ${ }^{(111,112)}$.This scale was used to assess students' satisfaction and self-confidence with the simulation-based learning and traditional teaching methods immediately after its application.

It consisted of 13 items. The 13 item instrument was answered using a five point Likert-type scale that ranged from "strongly disagree" to "strongly agree. The satisfaction subscale consisted of five items that were added to measure satisfaction with current learning. The selfconfidence subscale consisted of eight items.

\section{Scoring system:}

$1=$ Strongly disagree.

$2=$ Disagree .

$3=$ Undecided - neither agree nor disagree.

4= Agree with the statement.

$5=$ Strongly agree with the statement.

The scale was modified and three items were grouped together to help the 
statistical analysis of data and show the statistical difference in results, as the sample size is small.

\section{The new scoring system:}

$1=$ Disagree with the statement.

$2=$ Agree with the statement .

$3=$ Strongly agree with the statement.

\section{Tool III. General Self-efficacy Scale:}

This scale was developed by Schwarzer and Jerusalem (1995) for Adolescents and adults ${ }^{(113,114)}$. A 10 item scale was used to assess a general sense of perceived selfefficacy as follows:

\section{Rating Scale:}

$1=$ Not at all true

$2=$ Hardly true

3 = Moderately true

4= Exactly true

\section{Tool IV: Pediatric Injection}

\section{Administration Observational Checklist:}

This tool was developed by the researchers after reviewing the related literature. It was used to assess the students' clinical performance during intravenous, intramuscular and subcutaneous pediatric injection administration.

The observational checklist included the following:

\section{Intravenous injection sites:}

The top of the hand, the lower forearm, the upper, inner forearm near the fold of the elbow, the large jugular vein in the neck, veins in the foot, and veins of the scalp.

\section{Intramuscular injection sites:}

Vastuslateralis, ventrogluteal, dorsogluteal, deltoid, and rectus femoris.

\section{Subcutaneous injection sites:}

The outer aspect of the upper arms, the abdomen from below the coastal margins to the iliac crests, the anterior aspect of the thigh, scapular area of the upper back, and the upper ventral or dorsal gluteal area.

The students were assessed during the five performance categories:

Assessment, preparation, implementation, after care, and documentation.

\section{Scoring system:}

Scoring system of the students' performance towards each step in intravenous, intramuscular, and subcutaneous injection administration was as follows:

-Correct and complete done was scored (1).

-Not done or wrong done was scored (zero).

The total score of the students' performance equal $100 \%$ and accordingly the students' performance was classified as follows:

-Done correctly (60\% and more).

- Not done or wrong done (less than 60\%).

The researcher assessed the students' practice regarding pediatric injection administration three times:

1) Immediately following sessions (immediate follow up) 
2) Two weeks later (short term follow up)

3) Eight weeks later (medium term follow up).

\section{Method}

The study was accomplished through the following steps:

1. Administrative process: An official permission to conduct the study was obtained from the responsible authorities. Meeting with students who participated in the study to explain purpose of the study. The data was collected over a period of five months from August 2014 to December 2014. Four tools were used in this study:-

\section{Ethical considerations: Students'} privacy and confidentiality was protected. The obtained information was confidential and used only for purpose of the study. Students' consent to participate in this study was obtained.

\section{Pilot study:-}

A pilot study was carried out on $10 \%$ of the study sample to test clarity and applicability of the study tools then the necessary modification was done. The pilot study was excluded from the study sample.

\section{Phases of the actual study}

The studied students were divided into control and study group in the study setting using cluster randomization. Participants in the control group were taught by traditional teaching in clinical skills laboratory and participants in the study group were taught using simulationbased learning module in the clinical skills laboratory. The simulation-based learning module was carried out for the study group through conduction of successive sessions according to the actual needs and assessment of the studied students.

\section{- Assessment phase:}

Initial assessment of students' knowledge regarding pediatric injection administration was carried out prior to teaching sessions for both groups using tool I.

\section{- Implementation phase:}

The steps of simulation-based learning included:

a- Setting objective

b- Preparation of the content which covered the reason behind the application of the sessions.

c-The simulation-based learning module was conducted in 4 sessions in the clinical skills laboratory, two per week. The time of each session was about 30 minutes.

d- Different methods of teaching were used including lectures and power point for the control group and simulation-based learning module, demonstration and redemonstration for study group.

e- Teaching sessions for study group were as follows:

1. First session: It focused on: different sites of pediatric injection administration, 
general guidelines for pediatric injection administration, methods of injection administration, techniques of intravenous, intramuscular and subcutaneous pediatric injection administration, nursing role in pediatric injection administration, and advantages \&disadvantages of IV, IM, SC injection administration. The researcher assessed the students' knowledge regarding pediatric injection administration four times:

1) Before teaching sessions.

2)Immediately following sessions (immediate follow up)

3) Two weeks later (short term follow up)

4)Eight weeks later (medium term follow up).

\section{Second session:}

Simulation-based learning module for intravenous injection administration.

\section{Third session:}

Simulation-based learning module for intramuscular injection administration.

\section{Fourth session:}

Simulation-based learning module for subcutaneous injection administration.

The researcher assessed the students' practice regarding pediatric injection administration three times:

1) Immediately following sessions (immediate follow up)

2) Two weeks later (short term follow up)

3) Eight weeks later (medium term follow up).

\section{Evaluation phase:}

Evaluation was done three times after implementation of teaching to evaluate the effect of simulation-based learning on nursing students' clinical performance, satisfaction, self-efficacy and confidence during pediatric injection administration and was compared with control group.

\section{Statistical analysis:}

The collected data was organized, tabulated and statistically analyzed using SPSS software (Statistical Package for the Social Sciences, version 16, SPSS Inc. Chicago, IL, USA). For quantitative data, the range, mean and standard deviation were calculated. For qualitative data, comparison between two groups and more was done using Chi-square test $\left(\mathrm{X}^{2}\right)$. For comparison between means of two groups of parametric data of independent samples, student t-test was used. For comparison between more than two means of parametric data, $F$ value of ANOVA test was calculated for parametric data, where Scheffe test was performed to compare between each two means if $F$ value was significant. Significance was adopted at $\mathrm{P}<0.05$ for interpretation of results of tests of significance ${ }^{(115)}$.

\section{Limitations of the study}

- It was difficult to collect students after two and eight weeks to assess the retention of knowledge and evaluate 
their clinical performance in pediatric injection administration.

- Repetition of teaching more than one time due to the absenteeism of some students from the related clinical training.

- Students had different and unequal clinical experience that might alter the results of the study.

- Outcomes might be influenced by extraneous variables such as the outside employment of students or previous working in the health care setting, and their life experiences.

\section{Results}

Table (1) shows the percentage distribution of the studied students according to sociodemographic characteristics. It was observed that slightly more than two thirds of students $(69.3 \%)$ in the control group were aged 20 years old compared to $49.3 \%$ in the study group with a mean age $20.36 \pm 0.58$ and $20.59 \pm 0.64$ years in the control and study group respectively. Regarding sex of students, most of them were females $93.3 \%$ in the study group and $61.3 \%$ in the control group.

The table also reveals that more than threequarters of students $(80.0 \%)$ in the control group came from rural areas compared with $66.7 \%$ in the study group. It was observed that $80.0 \%, 68.0 \%$ of students in the control and study group respectively had attended the related clinical training.
Table (2) shows the percentage distribution of the studied students regarding their total satisfaction immediately after teaching. The majority of students in the study group $(100 \%)$ were satisfied with the simulationbased teaching method while $93.3 \%$ of students in the control group were unsatisfied with traditional teaching methods with significant difference was found between both groups (P-value 0.0001).

Table (3) illustrates the percentage distribution of studied students regarding their total self-confidence immediately after teaching. It was observed that $93.3 \%$ of students in the study group were confident after simulation-based teaching while 96.0\% of students in the control group were not confident after traditional teaching methods with statistically significant difference between both groups (P-value $0.0001)$.

Table (4) shows the percentage distribution of the studied students regarding their total perceived self-efficacy immediately after teaching. All students in the control group didn't perceive self-efficacy after traditional teaching, while the majority of students $(89.3 \%)$ in the study group had perceived self-efficacy immediately after simulationbased teaching with statistically significant difference in the total perceived self-efficacy between both groups (P-value 0.0001). Table (5) shows the mean scores of students' total knowledge regarding pediatric injection 
administration. It was observed that the mean scores of students' total knowledge regarding pediatric injection administration before teaching were 7.21 \pm 4.08 and $3.96 \pm 3.90$ in the study and control group respectively with statistically significant difference (P-value 0.0001).The table also reveals that there was no significant difference in the mean scores of students' total knowledge regarding pediatric injection administration in the study and control group (P-value 0.843).

It was evident that there was variation in the students' knowledge after two weeks of teaching with Mean \pm SD is $13.15 \pm 1.10$ in the study and $12.56 \pm 1.19$ in the control group with statistically significant difference between the two groups (P-value 0.002). In addition, the mean scores of students' knowledge after eight weeks of teaching were $12.53 \pm 1.08$ and $11.65 \pm 1.31$ in the study and control group respectively with statistically significant difference (P-value 0.0001).

Table (6) shows the percentage distribution of students' total performance in intramuscular pediatric injection administration. Regarding the level of students' total performance in intramuscular injection, all steps were done correctly immediately, two and eight weeks after simulation-based learning. On the other hand, $54.7 \%$ of steps were done correctly immediately after teaching but decreased to
$36.0 \%$ and $28.0 \%$ two and eight weeks respectively after traditional teaching with statistically significant difference (P-value 0.003) . It was evident that retention is higher after simulation-based teaching than traditional teaching. There was statistically significant difference between both groups (P-value 0.0001).

Figure (1) shows the percentage distribution of students' total performance in intravenous injection. Regarding the level of students' total performance in intravenous injection, all steps were done correctly immediately and two weeks after simulation-based learning compared to $97.3 \%$ after eight weeks. On the other hand, $72.0 \%$ of steps were done correctly immediately after traditional teaching but decreased to $53.3 \%$ and $33.3 \%$ two and eight weeks after traditional teaching respectively. It was evident that retention is higher after simulation-based teaching than traditional teaching. There was statistically significant difference between both groups (P-value 0.0001).

Figure (2) shows the percentage distribution of students' total performance in subcutaneous pediatric injection administration. Regarding the level of students' total performance in subcutaneous injection, all steps were done correctly immediately, two and eight weeks after simulation-based learning in the study group. 
On the other hand, $48.0 \%$ of steps were done correctly immediately after teaching but decreased to $22.7 \%$ and $8.0 \%$ respectively two and eight weeks after teaching. It was evident that retention is higher after simulation-based teaching than traditional teaching. There was statistically significant difference between both groups (P-value $0.000)$

Table (1): Percentage Distribution of the Studied Students According to Socio-Demographic Characteristics.

\begin{tabular}{|c|c|c|c|c|}
\hline \multirow{3}{*}{$\begin{array}{c}\text { Socio-Demographic } \\
\text { Characteristics }\end{array}$} & \multicolumn{4}{|c|}{$\begin{array}{l}\text { Percentage Distribution of the Studied Students } \\
(n=150)\end{array}$} \\
\hline & \multicolumn{2}{|c|}{$\begin{array}{c}\text { Study group } \\
(n=75)\end{array}$} & \multicolumn{2}{|c|}{$\begin{array}{c}\text { Control group } \\
(n=75)\end{array}$} \\
\hline & No & $\%$ & No & $\%$ \\
\hline \multicolumn{5}{|l|}{ Age (years): } \\
\hline - $20<$ & 37 & 49.3 & 52 & 69.3 \\
\hline - $\quad 21<$ & 32 & 42.7 & 19 & 25.3 \\
\hline - $22>$ & 6 & 6 & 4 & 5.3 \\
\hline $\begin{array}{l}\text { Range } \\
\text { Mean } \pm \text { SD }\end{array}$ & \multicolumn{2}{|c|}{$\begin{array}{c}20-22 \\
20.59 \pm 0.64\end{array}$} & \multicolumn{2}{|c|}{$\begin{array}{c}20-22 \\
20.36 \pm 0.58\end{array}$} \\
\hline \multicolumn{5}{|l|}{ Sex: } \\
\hline Males & 5 & 6.7 & 29 & 38.7 \\
\hline Females & 70 & 93.3 & 46 & 61.3 \\
\hline \multicolumn{5}{|l|}{ Residence: } \\
\hline Rural & 50 & 66.7 & 60 & 80.0 \\
\hline Urban & 25 & 33.3 & 15 & 20.0 \\
\hline \multicolumn{5}{|c|}{$\begin{array}{l}\text { Attendance of related clinical } \\
\text { training: }\end{array}$} \\
\hline No & 24 & 32.0 & 15 & 20.0 \\
\hline Yes & 51 & 68.0 & 60 & 80.0 \\
\hline
\end{tabular}

Table (2): Percentage Distribution of the Studied Students Regarding their Total Satisfaction Immediately after Teaching. 


\begin{tabular}{|l|c|c|c|c|c|c|}
\hline & \multicolumn{2}{|l|}{$\begin{array}{l}\text { Study group } \\
\text { (SBL) } \\
\text { (n=75) }\end{array}$} & \multicolumn{2}{c|}{ Control group } & Test & P \\
\hline & No & \% & No & \% & & \\
\hline Unsatisfied & 0 & 0 & 70 & 93.3 & 131.250 & $0.0001^{*}$ \\
\hline Satisfied & 75 & 100 & 5 & 6.74 & & \\
\hline
\end{tabular}

\section{Statistically significant at $\mathbf{P}<0.05$}

Table (3): Percentage Distribution of Studied Students Regarding Their Total Self-Confidence Immediately after Teaching.

\begin{tabular}{|c|c|c|c|c|c|c|}
\hline \multirow{3}{*}{$\begin{array}{c}\text { Level of total } \\
\text { self-confidence }\end{array}$} & \multicolumn{4}{|c|}{$\begin{array}{l}\text { Total Self-Confidence of Studied Students } \\
\text { Immediately after Teaching. }(n=150)\end{array}$} & \multirow[b]{2}{*}{ test } & \multirow[b]{2}{*}{$\mathbf{P}$} \\
\hline & \multicolumn{2}{|c|}{$\begin{array}{l}\text { Study group (SBL) } \\
\qquad(\mathrm{n}=75)\end{array}$} & \multicolumn{2}{|c|}{$\begin{array}{l}\text { Control group } \\
\qquad(n=75)\end{array}$} & & \\
\hline & No & $\%$ & No & $\%$ & & \\
\hline Not confident & 5 & 6.7 & 72 & 96.0 & 119.792 & $0.0001^{*}$ \\
\hline Confident & 70 & 93.3 & 3 & 4.0 & & \\
\hline
\end{tabular}

Table (4): Percentage Distribution of the Studied Students Regarding their Total Perceived Self-Efficacy Immediately after Teaching.

\begin{tabular}{|c|c|c|c|c|c|c|}
\hline \multirow{3}{*}{$\begin{array}{l}\text { Level of total } \\
\text { perceived self- } \\
\text { efficacy }\end{array}$} & \multicolumn{4}{|c|}{$\begin{array}{l}\text { Total Perceived Self-Efficacy of the Studied } \\
\text { Students Immediately after Teaching.(n=150) }\end{array}$} & \multirow{3}{*}{ test } & \multirow{3}{*}{$\mathbf{P}$} \\
\hline & \multicolumn{2}{|c|}{$\begin{array}{l}\text { Study group (SBL) } \\
\qquad(\mathrm{n}=75)\end{array}$} & \multicolumn{2}{|c|}{$\begin{array}{l}\text { Control group } \\
\qquad(\mathbf{n}=75)\end{array}$} & & \\
\hline & No & $\%$ & No & $\%$ & & \\
\hline Not perceived & 8 & 10.7 & 75 & 100 & 121.084 & $0.0001 *$ \\
\hline Perceived & 67 & 89.3 & 0 & 0 & & \\
\hline
\end{tabular}


Table (5): Mean Scores of Students' Total Knowledge Regarding Pediatric Injection Administration.

\begin{tabular}{|l|c|c|c|c|}
\hline & \multicolumn{2}{|l|}{$\begin{array}{l}\text { Students' Total Knowledge Regarding Pediatric } \\
\text { Injection Administration.(n=150) }\end{array}$} & Control group \\
$(\mathbf{n = 7 5 )}$ & t-test & P \\
\hline Time of assessment & $\begin{array}{l}\text { Study group } \\
\text { (Simulation-based learning) } \\
(\mathbf{n = 7 5 )}\end{array}$ & $\begin{array}{c}\text { Mean+SD } \\
\text { Mean } \pm \text { SD }\end{array}$ & & \\
\hline Pre-teaching & $7.21 \pm 4.08$ & $3.96 \pm 3.90$ & 4.992 & $0.0001^{*}$ \\
\hline $\begin{array}{l}\text { Immediately after } \\
\text { teaching }\end{array}$ & $12.87 \pm 1.27$ & $12.83 \pm 1.20$ & 0.198 & 0.843 \\
\hline $\begin{array}{l}\text { Two weeks after } \\
\text { teaching }\end{array}$ & $13.15 \pm 1.10$ & $12.56 \pm 1.19$ & 3.139 & $0.002^{*}$ \\
\hline $\begin{array}{l}\text { Eight weeks after } \\
\text { teaching }\end{array}$ & $12.53 \pm 1.08$ & $11.65 \pm 1.31$ & 4.485 & $0.0001^{*}$ \\
\hline $\begin{array}{l}\text { F } \\
\text { P value }\end{array}$ & 115.921 & 276.898 & & \\
\hline
\end{tabular}

Table (6): Percentage Distribution of Students' Total Performance in Intramuscular Pediatric Injection Administration.

\begin{tabular}{|c|c|c|c|c|c|c|c|c|c|c|}
\hline \multirow{4}{*}{$\begin{array}{c}\text { Time of } \\
\text { assessment }\end{array}$} & \multicolumn{8}{|c|}{$\begin{array}{l}\text { Students' Total Performance in Intramuscular } \\
\text { Pediatric Injection Administration. }(n=150)\end{array}$} & \multirow{4}{*}{$\begin{array}{c}2 \\
\text { Test }\end{array}$} & \multirow[t]{4}{*}{$\mathbf{P}$} \\
\hline & \multicolumn{4}{|c|}{$\begin{array}{c}\text { Study group } \\
\text { (simulation-based } \\
\text { learning) } \\
(\mathbf{n}=75)\end{array}$} & \multicolumn{4}{|c|}{$\begin{array}{l}\text { Control group } \\
(n=75)\end{array}$} & & \\
\hline & \multicolumn{2}{|c|}{$\begin{array}{l}\text { Not done } \\
\text { or wrong } \\
\text { done }\end{array}$} & \multicolumn{2}{|c|}{$\begin{array}{c}\text { Done } \\
\text { correctly }\end{array}$} & \multicolumn{2}{|c|}{$\begin{array}{c}\text { Not done } \\
\text { or wrong } \\
\text { done }\end{array}$} & \multicolumn{2}{|c|}{$\begin{array}{c}\text { Done } \\
\text { correctly }\end{array}$} & & \\
\hline & No & $\%$ & No & $\%$ & No & $\%$ & No & $\%$ & & \\
\hline $\begin{array}{l}\text { Immediately } \\
\text { after teaching }\end{array}$ & 0 & 0 & 75 & 100 & 34 & 45.3 & 41 & 54.7 & 41.240 & $0.0001 *$ \\
\hline $\begin{array}{l}\text { Two weeks after } \\
\text { teaching }\end{array}$ & 0 & 0 & 75 & 100 & 48 & 64.0 & 27 & 36.0 & 67.580 & $0.0001 *$ \\
\hline $\begin{array}{l}\text { Eight weeks } \\
\text { after teaching }\end{array}$ & 0 & 0 & 75 & 100 & 54 & 72.0 & 21 & 28.0 & 81.260 & $0.0001 *$ \\
\hline $\begin{array}{l}{ }^{2} \text { test } \\
\mathrm{P}\end{array}$ & \multicolumn{4}{|c|}{$\begin{array}{l}0.000 \\
1.000\end{array}$} & \multicolumn{4}{|c|}{$\begin{array}{l}11.750 \\
0.003 *\end{array}$} & & \\
\hline
\end{tabular}

Figure (1): Percentage Distribution of Students' Total Performance in Intravenous Injection. 
Figure (2): Percentage Distribution of Students' Total performance in Subcutaneous Pediatric Injection

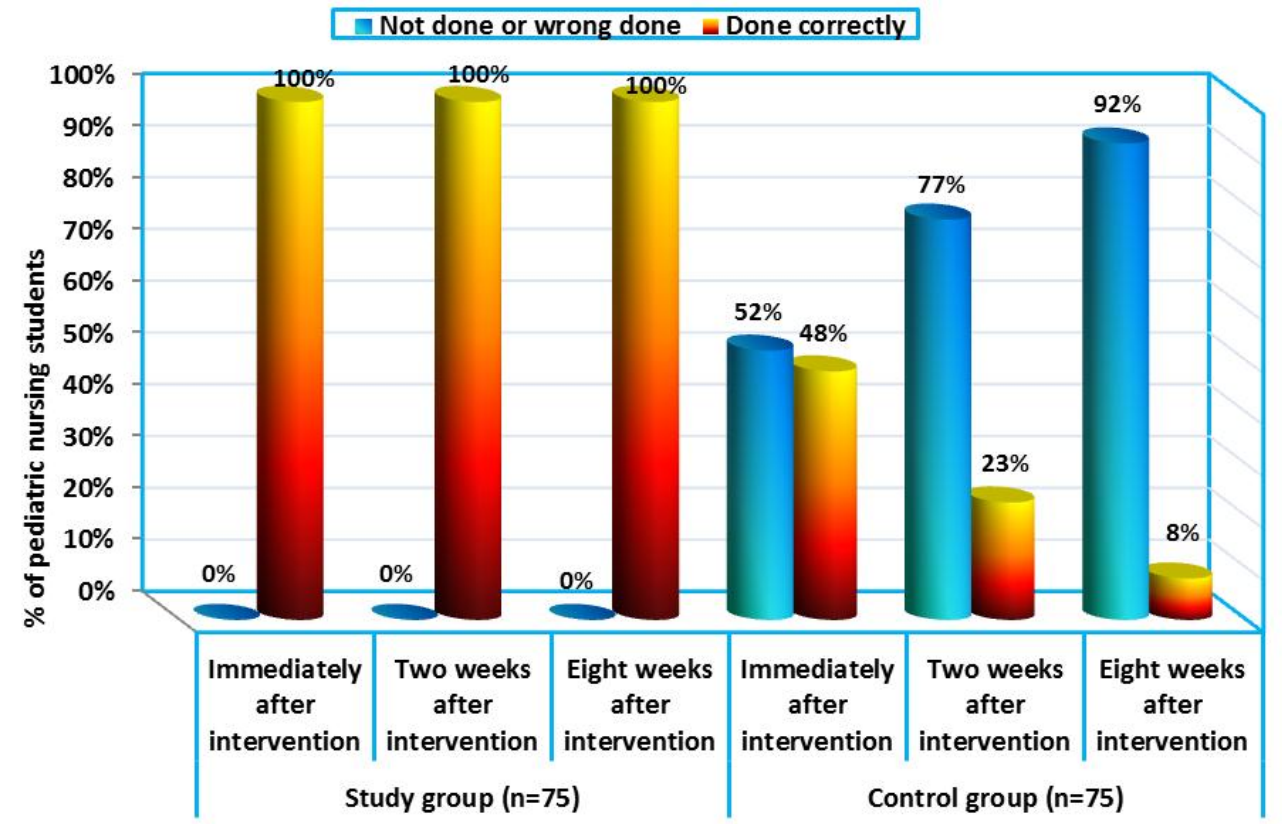

Level of total performance of pediatric administration of SC injection $(n=150)$

Such constraints affect a nursing student's ability

\section{Discussion}

Although learning by doing is a long established means for facilitating knowledge acquisition, it is not always practical or costeffective to engage in skill training with real patients because of the increased acuity of to develop the necessary clinical competence to care for patients. Fortunately, patient simulators provide a very realistic substitute situation ${ }^{(19)}$.

Regarding socio-demographic data of the studied third year pediatric nursing students, 
in relation to sex, the present study revealed that most of students in the study and control group were females. This is due increased number of females who are admitted to the faculty and males are newly admitted in few numbers. This result is in agreement with the study of Valizadeh (2013) in which most of the students in the control, demonstration, and study group were females ${ }^{(20)}$. The study result is also congruent with Hall (2013) who reported that $90.7 \%$ of the studied students were females and only $9.3 \%$ of them were males ${ }^{(21)}$.

Regarding age of students involved in this study, it was observed that $69.3 \%$ of students in the control group and $49.3 \%$ of them in the study group were aged 20 years while $42.7 \%$ of students in the study group were aged 21 years. The study result is in agreement with Hall (2013) whofound that $65.1 \%$ of students were between $18-21$ years while, $30.3 \%$ of them were between $22-25$ years ${ }^{(21)}$.

The current study figured out that there was a significant improvement in students' total knowledge about pediatric injection administration after simulation-based and traditional teaching methods in both groups, but this improvement was higher in the study than the control group. The improvement in students' knowledge may be due to the use of combination of various instructional methods in addition to simulation in the study group.
The present study is congruent with Rethans(2012) who found that the intervention group had a significant higher post-test mean score than the control group for knowledge and clinical performance ${ }^{(22)}$. The study of Prion\&Pauly (2013) revealed that there was a rise in knowledge about essential medication administration skills for the pediatric population after simulationbased learning ${ }^{(23)}$. In addition, the study of Babenko (2015)suggested that nursing students acquired necessary knowledge and skills for safe injection administration through the combination of simulated practice and participation in an actual vaccination clinic ${ }^{(24)}$.

The current study results are incongruent with Shepherd (2010) who determined that there was no significant difference in cognitive gains of the two groups of nursing students exposed to simulation and traditional teaching ${ }^{(25)}$.

In relation to the level of total satisfaction of pediatric nursing students with simulationbased and traditional teaching methods, the current study showed that all students in the study group were satisfied with simulationbased learning, while most of them were unsatisfied with traditional teaching method. This result can be explained in the light of the benefit of simulation that contributes to developing clinical skills and confidence of nursing students in practice. It also can increase students' confidence and better 
prepare them for the clinical practice. Therefore, the student satisfaction is high.

This result is in agreement with Tuttle (2009)who reported that there was a significant difference in learner satisfaction which is higher in the experimental group that used simulation-based learning (26). Another study carried out by Parker (2011) showed that using the simulation technique leads to increased satisfaction and selfconfidence of students ${ }^{(27)}$. In addition to this study, Khan (2015) reported that most of students were satisfied that simulation-based learning improved their knowledge retention, skills, and communication and provided a conductive learning environment (28).

Regarding self-confidence of the studied third year pediatric nursing students, the current study revealed that there was highly significant difference in self-confidence between the study and control group. The study reported that self-confidence of pediatric nursing students had increased significantly after simulation-based learning. A study done by Prion \&Pauly (2013) also reported that there was a rise in students' self-reporting of confidence regarding essential medication administration skills for pediatric population as a result of simulation-based learning ${ }^{(23)}$.

This study was also congruent with Valizadeh (2013)who demonstrated that the simulation method leads to a significant increase in self-confidence of students compared to the lecture method using slides and images ${ }^{(20)}$.

In relation to the total perceived self-efficacy of pediatric nursing students, the current study revealed that the students in the study group reported increased self-efficacy after simulation-based learning than traditional teaching. The study results were in accordance with Ran (2011) who found that simulation-based learning was a useful method for practical ability and this is good to acquire both knowledge and technique ${ }^{(29)}$. Moreover, the study of Babenko (2015) suggested that nursing students acquired necessary knowledge and skills and had high self-efficacy after simulation-based learning (24). The findings of Tuttle (2009) also indicated that when the two groups were compared to each other, the experimental group had a higher clinical self-efficacy score ${ }^{(26)}$.

Regarding the students' total performance in intravenous injection, there was a statistically significant difference in the performance of students regarding intravenous injection in both groups. The level of total performance is higher after simulation-based learning than traditional teaching method. These results are congruent with Mosser\& Stephens (2013) who found that through the use of simulation technology and debriefing techniques at the pediatric Peripheral Intravenous (PIV) 
insertion program, PIV insertion skills of medical-surgical nursing staff improved, as evidenced by a decreased number of pediatric PIV insertion attempts ${ }^{(30)}$.

Regarding the students' total performance in subcutaneous injection, there was a highly significant difference between the performances of students in both groups. The level of total performance was higher after simulation-based learning than traditional teaching method. This study is in agreement with Seong (2010) who confirmed that the teaching method using standardized patients was more effective than the traditional method to improve nursing students' competence, self-directed learning readiness, and problem solving (31). Therefore, it is necessary to develop various scenarios, to testify their effectiveness, and to apply standardized patients for health assessment.

The training conducted in the simulated environment may offer an additive benefit to the traditional instruction and enhance performance. Simulation-based learning improved the performance of pediatric nursing students regarding intravenous, intramuscular, and subcutaneous injection administration compared to traditional teaching.

\section{Conclusion}

Based on the results of the present study, it can be concluded that there was a significant improvement in pediatric nursing students' performance regarding intravenous, intramuscular, and subcutaneous pediatric injection administration after simulation-based learning. The level of student's satisfaction, confidence, and self-efficacy was very high after simulation-based learning and they found it an effective instructional technique.

\section{Recommendations}

Based on the findings of the present study, the following recommendations are suggested:

- Nursing education programs should adopt simulation in undergraduate education, and should support the introduction of SBL as an important step in curriculum development

- It is necessary to determine the best size of student groups to promote effective student learning using simulation.

- This study should be replicated with more participants and at several universities to determine measurable outcomes of simulation and to generate larger statistical power with a diverse group of students.

- Research studies need to be conducted to see if simulation has an impact on transfer of learning to the clinical environment and to fully understand the role of simulation in nursing education.

\section{References}

1. Berragan L. Learning nursing through simulation: A case study approach towards an expansive model of learning. 
Journal of Nurse Education Today 2014; 34(8):1143.

2. Tanner C. Thinking like a nurse: A research-based model for clinical judgment in nursing. Journal of Nursing Education 2011; 45(9): 204-11.

3. Galbraith M. Adult Learning Methods: A Guide for Effective Instruction.3rd ed. London: Krieger Pub. Co., 2015; 200-11.

4. Sinclaire B, Ferguson K. Integrating simulated teaching/learning strategies in undergraduate nursing education. International Journal of Nursing Education Scholarship 2009; 6(1):1-11.

5. Nagle M, Alexander A, French $M$. Incorporating scenario-based simulation into a hospital nursing education program. Journal of Continuing Education in Nursing 2009; 40(1):1825.

6. Bambini D, Washburn J, Perkins R. Outcomes of clinical simulation for novice nursing students: communication, confidence, clinical judgment. Journal of Nursing Education Perspectives 2009; 44(9):421-25.

7. Bremner $\mathrm{M}$, Aduddell $\mathrm{K}$, Bennett $\mathrm{D}$, Vangeest J. The use of human patient simulators: best practice with novice nursing students. Nurse Educator Journal 2006; 31(2):170-4.

8. Levine A, Schwartz A, Sim A. The Comprehensive Textbook of Health
Care Simulation. 2nd ed. United States of America: Springer Publishing Co., 2014; 5, 73-89, 173, 495-505.

9. Hale T, Ahlschlager P. Simulation Scenarios for Nursing Education. 1sted. New York: DelmorCengage Learning Co., 2010; 5-25.

10. Hannenman E, Cunningham H. Using clinical simulation to teach patient safety in an acute care nursing course. Journal of Nurse Educator 2005; 40(30):172-77.

11. Leigh T. High-fidelity patient simulation and nursing students' selfefficacy: a review of the literature. International Journal of Nursing Education Scholarship 2008; 37(5):6069.

12. Diehl C. Simulation in healthcare and nursing: state of the science. Journal of Critical Care Nursing Quarterly 2009; 32(2): 128-36.

13. Kneebone R. Evaluating clinical simulations for learning procedural skills: a theory-based approach. Academic Medicine Journal 2005; 80(6): 549-53.

14. Hoffmann L, Kim Y, Donnel M. The effects of human patient simulators on basic knowledge in critical care nursing with undergraduate senior baccalaureate nursing students. Simulation in Healthcare: Journal of Society for 
Simulation in Healthcare 2007; 2(1): 110-15.

15. Nehring W, Lashely F. Nursing simulation: a review of the past 40 years. Journal of Interprofessional Education \& Practice 2009; 40(4): 528-52.

16. Wotton K, Davis J, Button D, Kelton M. Third-year undergraduate nursing students' perceptions of high-fidelity simulation. The Journal of Nursing Education 2010; 49(11): 632-39.

17. Orland L, Wilhelem D. Novices in clinical practice setting: student nurses stories of learning the practice of nursing. Journal of Nurse Education Today 2010; 25(7): 455-64.

18. Kearsley G, Marquardt M. TechnologyBased Learning: Maximizing Human Performance and Corporate Success. 5th ed. United States of America: CRC Press Co., 2009; 131-42.

19. Doerr H, Murray W. How to build a successful simulation strategy: the simulation learning pyramid. Elsevier Academic Press Journal 2008; 771-85.

20. Valizadeh L, Azar E, Akbarzadeh B, Amini A. The effects of simulation teaching on baccalaureate nursing students' self-confidence related to peripheral venous catheterization in children: a randomized trial. Journal of Caring Sciences 2013; 2(2): 157-64.

21. Hall R. Effects of high-fidelity simulation on knowledge acquisition, self-confidence, and satisfaction with Baccalaureate nursing students using Solomon-four research design. (2013). Electronic Theses and Dissertations. Paper 2281.Available At: http://dc.etsu.edu/etd/HYPERLINK "http://dc.etsu.edu/etd/2281"2281.

22. Rethans J, Liaw S, Scherpbier A, Yobas P. Assessment for simulation learning outcomes: a comparison of knowledge and self-reported confidence with observed clinical performance. Journal of Nurse Education Today 2012; 32(6): 35-9.

23. Prion S, Pauly S. Using integrated simulation in a nursing program to improve medication administration skills in the pediatric population. Journal of Nursing Education Perspectives 2013; 34(3): 148-53.

24. Babenko Y, Ferguson K, Riddell T. Influence of simulated and actual community clinics on students' empowerment and self-efficacy for public health nursing competencies. Journal of Public Health Nursing 2015; 32(3): 277-83.

25. Shepherd C, Brown L, Hair M. Investigating the use of simulation as a teaching strategy. Nursing Standard Journal 2010; 24(35): 42-8.

26. Tuttle R. The impact of simulation in nursing education on the self-efficacy and learner satisfaction of nursing 
students. Faculty Scholarship Nursing

Journal 2009; 32(3): 127-32.

27. Parker A, Mcneill A, Pelayo W, Gunter

D. Pediatric clinical simulation: a pilot project. Journal of nursing Education 2011; 50(2): 105-11.

28. Khan M, Agha S, Alhamrani A. Satisfaction of medical students with simulation based learning. Saudi Medical Journal 2015; 36(6): 731-6.

29. Ran H, Young K, Min S. The relationship among learning satisfaction, learning attitude, self-efficacy, and the nursing students' academic achievement after simulation-based education on emergency nursing care. Journal of Korean Academic Society of Nursing Education 2011; 17(1): 5-13.

30. Mosser N, Stephens K. Simulation to improve pediatric patient outcomes: university and hospital collaborative. Journal of Clinical Simulation in Nursing 2013; 9(7): 243-7.

31. Seong K, Eom R, Sook H, Kyung E. Effects of teaching Method using standardized patients on nursing competence in subcutaneous injection, self-directed learning readiness, and problem solving ability. Journal of Korean Academy of Nursing 2010; 40(2): 151-60. 
